Revista lus et Praxis, Año 17, No 2, 2011, pp. 119 - 132

ISSN 0717 - 2877

Universidad de Talca - Facultad de Ciencias Jurídicas y Sociales

"Lo circunstancial en los delitos imprudentes.

Una visión desde el ordenamiento punitivo cubano"

Dayan López Rojas

\title{
LO CIRCUNSTANCIAL EN LOS DELITOS IMPRUDENTES. UNA VISIÓN DESDE EL ORDENAMIENTO PUNITIVO CUBANO*
}

\author{
THE CIRCUMSTANCES IN THE RECKLEES CRIMES. \\ A SIGHT FROM THE PENAL CUBAN SYSTEM
}

Dayan LÓPEZ ROJAs**

\begin{abstract}
RESUMEN
La investigación se orienta a un análisis dogmático en torno a la compatibilidad entre algunas circunstancias modificativas de la responsabilidad penal y los delitos imprudentes desde una perspectiva sistemática, a partir de los postulados que ofrece la teoría general de las circunstancias modificativas de la responsabilidad penal.

El estudio doctrinal que se lleva a cabo, cuyo propósito es analizar las bases jurídicas esenciales que permitan la justa interpretación y apreciación de lo circunstancial en el delito imprudente, afronta el tratamiento que tradicionalmente ha ofrecido la práctica judicial cubana a la cuestión examinada; y con apoyo en las razones que fundamentan las circunstancias modificativas de la responsabilidad penal, se sustenta la compatibilidad entre los delitos cometidos por imprudencia y aquellas atenuantes que obedezcan a razones de política criminal.
\end{abstract}

ABSTRACT

The article it finds one's bearings to a dogmatic analysis about compatibility between modifying circumstances of criminal responsibility and reckless crimes from a systematic perspective, as of the postulates that offers the general theory of the modifying circumstances of criminal responsibility.

The doctrinal study that it takes to end, faces the treatment that traditionally has offered the judicial Cuban practice to the examined question, and with support in the reasons that lay the foundations of the modifying circumstances of the penal responsibility sustains to him the compatibility between the crimes committed for imprudence and those attenuating that obey reasons of criminal politics.

PaLABRAS CLAVE

Circunstancia Modificativa de la Responsabilidad Penal, Compatibilidad Delito Imprudente

KEY WORDS

Modifying Circumstances of Criminal Responsibility, Compatibility, Reckless Crimes.

\footnotetext{
* Trabajo recibido el 19 de julio y aprobado el 17 de septiembre de 2011.

** Licenciado en Derecho; Profesor de Derecho Penal, Universidad de Matanzas "Camilo Cienfuegos". Cuba. Correo electrónico: Correos electrónicos: dayo30@enet.cu.
} 
La temática circunstancial es, sin dudas, de las más apasionantes dentro de la dogmática penal. Del debate a que son sometidas por las partes y de la valoración que respecto a ellas realice el órgano judicial, depende, en buena medida, que el resultado del juzgamiento se concrete en la imposición de una sanción justa y ponderada, en armonía con los principios que rigen su individualización.

La evolución histórica de la determinación de la pena ha estado influida por el desarrollo doctrinal de las circunstancias modificatorias de la responsabilidad. Según COBO y VIVEs, "las circunstancias nacieron con apoyo del juicio de individualización de la pena y para cumplir un objetivo de gran alcance, ya que ponen de manifiesto su concepción gradativa en referencia con el delito y la personalidad del delincuente, afirmando, a su vez, la individualidad y personalismo que debe presidir la responsabilidad criminal, expresión de un proceso de subjetivación de un Derecho penal evolucionado"1.

Hoy día, gracias a los avances alcanzados en el análisis de la estructura del delito por las tendencias causal-valorativa y finalista, se ha logrado determinar con meridiana precisión las nociones de antijuricidad y de culpabilidad, lo que ha propiciado el desarrollo del estudio de las circunstancias modificatorias con el objeto de aplicar penas justas y proporcionadas a la gravedad y trascendencia social del hecho y a los fines de la pena ${ }^{2}$.

De este modo, el sujeto delincuente pasa a tener especial consideración, porque la sanción penal debe guardar estricta proporcionalidad con la gravedad del injusto y la intensidad del reproche que merece el responsable, valorando además razones político-criminales. Las circunstancias modificatorias tienen precisamente esa finalidad: determinar la mayor o menor gravedad del delito, la intensidad del juicio de reproche y las necesidades político criminales.

Dentro del estudio de la teoría general de las circunstancias modificativas de la responsabilidad penal, se dedica un espacio al estudio y explicación de lo relativo a la compatibilidad, en cuya sede se analiza la relación que guardan las circunstancias con el hecho o entre sí.

No resulta posible aplicar una circunstancia que excluye conceptualmente a otra, o al tipo mismo de delito. Se habla entonces de incompatibilidad, que puede darse entre delitos y circunstancias, o entre circunstancias.

Uno de los supuestos de incompatibilidad que más se discute es el relacionado con la apreciación de circunstancias modificativas en los delitos cometidos por imprudencia, siendo criterio extendido en la doctrina la imposibilidad de

\footnotetext{
1 Apud. Cobo del Rosal, Manuel; Tomás S. Vives Antón, Derecho Penal, Parte General, 2a Edición, Editorial Tirant Lo Blanch, Valencia, 1988, p. 610.

2 Vid. Garrido Montt, Mario, Derecho Penal, Parte General, Tomo I, 1ª Edición, Editorial Jurídica de Chile, Santiago-Chile, 2001, p. 177.
} 
"Lo circunstancial en los delitos imprudentes. Una visión desde el ordenamiento punitivo cubano"

apreciar en estos casos circunstancias de atenuación y agravación genéricas, por resultar incompatibles con el tipo imprudente.

Esta postura, asumida como dominante por la jurisprudencia tradicional del Tribunal Supremo cubano, hoy merece ser sometida a un replanteo, en coherencia con el sostenimiento de una teoría general de las circunstancias modificativas de la responsabilidad penal.

Para ello se requiere, en primer término, hacer un somero esbozo sobre algunas cuestiones esenciales de la teoría general de las circunstancias modificativas de la responsabilidad penal, en aras de sustentar nuestro criterio sobre el asunto en comentario.

\section{El estudio sobre las CirCunstancias modificativas. Estado de la cuestión}

Actualmente, se reconoce dentro del círculo de la dogmática jurídico-penal que la Teoría General de la Circunstancias Modificativas de la Responsabilidad Criminal se halla en un verdadero estado de semi-abandono, pues salvo puntuales excepciones ${ }^{3}$, estas sólo han sido objeto del escaso estudio que la ha brindado la Parte General de la manualística. Sin embrago, no puede decirse lo mismo en lo referido al análisis de las circunstancias en particular, pues casi todas han sido tratadas en excelentes trabajos monográficos de autores, en su mayoría españoles ${ }^{4}$.

Pero la ausencia de sólidas bases en lo referido a una teoría general sobre la temática analizada se ha convertido en su "talón de Aquiles". Contra estos

\footnotetext{
3 En este sentido se ha manifestado Mercedes Alonso Álamo, quien sostiene que en la dogmática penal actual "no aparece suficientemente atendido el estudio general, sistemático, de las circunstancias del delito". Cfr. Alonso Álamo, Mercedes, "Circunstancias del delito e inseguridad jurídica", Cuadernos y Estudios de Derecho Judicial, Consejo General del Poder Judicial, Edición Especial para IBERIUS, 2004.

${ }^{4}$ Entre los múltiples estudios que se han proyectado sobre las circunstancias concretas en la doctrina extranjera pueden señalarse: Alcalá-Zamora y CASTILlo, N., El desistimiento espontáneo y el arrepentimiento activo:(memoria doctoral), Ed. Imprenta del Colegio Nacional de Sordomudos y de Ciegos, Madrid, 1928; A Lonso Fernández, J.A., Los estados pasionales y su incidencia en la culpabilidad análisis jurisprudencial de la circunstancia atenuante de arrebato u obcecación, Ed. Bosch, Barcelona, 1999; Altés Martí, M.A., La alevosía: (estudio de determinados aspectos de la agravante del Art. 10 del Código Penal), Ed. Universidad de Valencia, 1982; AмAT y FurıO, V., La embriaguez ante la ciencia penal. BAjO Fernández, M., El parentesco en el Derecho Penal, Barcelona, 1973; El disfraz y su comunicabilidad, en Circunstancias Modificativas de la responsabilidad criminal. Director LoRenzo del Río FeRnÁNDEZ (Cuadernos de Derecho Judicial, 1995, 7) Cortés BeChiarellı, E., Arrebato u obcecación: circunstancias atenuantes, Ed. Marcial Pons, Madrid, 1997. Recientemente se han ocupado de esta temática en el ámbito patrio los reconocidos profesores Carlos Alberto Mejías RodríGuez y Danilo Rivero García. Véase del primero de ellos su trabajo "Concepto, naturaleza jurídica y elementos de la alevosía en el derecho penal cubano". (versión digitalizada); y del segundo, los Artículos "¿vida ejemplar o vida destacada?" y "¿Espontánea confesión o ayuda al esclarecimiento? Polémica entre el discurso legal y la práctica". Rivero García, Danilo, Temas permanentes del Derecho Procesal y del Derecho Penal, Ediciones ONBC, La Habana, 2010, pp. 161-178 y 180-199.
} 
estudios sobre circunstancias específicas conspira la enorme disparidad de criterios relacionados con aspectos sustanciales, como la delimitación del propio concepto de circunstancia, su naturaleza jurídica, su fundamento, la clasificación, la comunicabilidad o compatibilidad entre ellas, el error, y otras categorías; lo que ha conducido a González Cussac sostenga que "las circunstancias modificativas, tanto en su significado dogmático, técnico, como político criminal, constituyen un semillero de no pocas controversias"

\section{CONCEPTO DE CIRCUNSTANCIAS MODIFICATIVAS DE LA RESPONSABILIDAD PENAL. LOS ELEMENTOS TÍPICOS ACCIDENTALES}

En la vida cotidiana tienen lugar variadísimos comportamientos humanos que resultan reñidos con determinados bienes jurídicos. El Derecho Penal moderno, erigido sobre su función preventivo-protectora, respetuoso de las garantías individuales del ciudadano, encuentra justificación en la tutela jurídica fragmentaria de aquellos bienes jurídicos cuya protección resulta indispensable para la realización del individuo dentro de la sociedad y el Estado ${ }^{6}$. Esta idea constituye el sustrato del principio de fragmentariedad e intervención mínima del Derecho penal, que tal y como ha puesto de manifiesto MIR PUIG, responde a la filosofía de lograr el "mayor bien social" con el "menor costo social", alcanzar la "máxima utilidad posible" con el "mínimo sufrimiento necesario"

Ante un acontecimiento jurídico-penalmente relevante es necesario llevar adelante un proceso de transformación jurídica de ese "hecho-bruto" al hecho individualizado, al "hecho definitivo", al tiempo que debe convertirse la "norma-bruta" en "norma particularizada", suficientemente concretizada para ser aplicable al hecho". En este sentido, explica GonzÁlez Cusacc que "junto a la parte principal del hecho, la que da lugar a la formulación de los juicios de antijuricidad y de culpabilidad, coexiste otra accesoria -al menos desde el punto

5 González Cussac, José L., Teoría General de las circunstancias modificativas de la responsabilidad Criminal, Editorial del servicio de Publicaciones de la Universidad de Valencia, 1983, p. 3. El estado de la cuestión ha llegado a tal punto que Сово y VIVEs han afirmado "que existe una gran disparidad y distanciamiento en la doctrina y un alto grado de incerteza en esta materia, disparidad, distanciamiento e incerteza de los que participan también, como no podía ser de otro modo, los pronunciamientos del Tribunal Supremo, y ello sobre aspectos tales como su naturaleza, su clasificación, su ubicación sistemática o su función, e incluso también sobre cuestiones no ya generales sino aspectos concretos de cada una de las circunstancias en particular". Сово, Derecho, cit. nota n. 1, p. 873.

6 Apud. Muñoz Conde, Francisco, García Arán, Mercedes, Derecho Penal, Parte General, 5a Edición, Editorial Tirant lo Blanch, Valencia, 2002, p. 72.

7 Mir Puig, Santiago, Derecho Penal, Parte General, 7ª Edición, Editorial Reppertor, Barcelona, 2005, p. 105.

8 Larenz, K,; Metodología de la Ciencia del Derecho, 2a Edición, Traducida de Rodríguez Molinero, M., Barcelona, 1980, p. 274. 
"Lo circunstancial en los delitos imprudentes. Una visión desde el ordenamiento punitivo cubano"

de vista jurídico-valorativo, que no desde el naturalístico, en el que ambos son iguales- que origina la teoría de las circunstancias modificativas" ${ }^{\prime \prime}$.

De lo anterior se concluye que las circunstancias modificativas de la responsabilidad penal constituyen elementos accidentales del delito (accidentalia delicti $^{10}$, en tanto no determinan su existencia, sino que sólo importan a los efectos de la gravedad de la infracción. Se trata de las denominadas circunstancias atenuantes y agravantes de la responsabilidad penal que, por regla general, afectan a las categorías esenciales del delito -injusto y culpabilidad-, disminuyendo o aumentando su cantidad, sin olvidar que en determinados casos su justificación responde a exclusivas razones de política criminal ${ }^{11}$.

\section{FUNDAMENTO Y UBICACIÓN SISTEMÁTICA DE LAS CIRCUNSTANCIAS MODIFICATIVAS DE LA RESPONSABILIDAD PENAL}

Quienes han pretendido hallar la justificación de por qué simples accidentes van a determinar un aumento o disminución de la pena, se han agrupado tradicionalmente en dos posiciones enfrentadas; y mientras unos atribuyen tales consecuencias a la modulación que las circunstancias determinan sobre las magnitudes que componen el ilícito -injusto y culpabilidad-, y sitúan su estudio dentro de la teoría del delito ${ }^{12}$, otros esgrimen argumentos político-

${ }^{9}$ González Cussac, José L., "Presente y Futuro de las Circunstancias Modificativas", Cuadernos y Estudios de Derecho Judicial, Consejo General del Poder Judicial, Edición Especial para IBERIUS, 2004.

${ }^{10}$ Como bien ha puesto de manifiesto González CuSSAC "su naturaleza jurídica es puramente accidental al no afectar a la sustancia (existencia misma) de la infracción, esto es, ni a la lesión o puesta en peligro del bien jurídico, ni a su posterior reproche. Se trata de elementos accidentales que pueden existir o no, y que pueden tener relevancia penal o no tenerla, a cuyos efectos resulta definitivo "el dato normativo". González, Presente, cit. nota n. 9.

11 Pero estas circunstancias atenuantes y agravantes que normalmente reconocen los Códigos en su Parte General -atenuantes y agravantes en sentido estricto- no son los únicos elementos accidentales de los que depende la gravedad del hecho, pues en la Parte Especial también se describen numerosos elementos que aumentan o disminuyen la pena. A estos últimos son los que Mir PUiG denomina «elementos típicos accidentales». Cfr. MIR, Derecho Penal, cit. nota n. 7, p. 602.

12 Una postura doctrinal -ya superada actualmente- se pronunció por estimar que las circunstancias, aún dentro de la teoría del delito, sólo influían dentro de la culpabilidad entendiendo que las mismas suponían una mayor o menor peligrosidad del sujeto. Estas concepciones respondían a la corriente positivista del Derecho Penal e imperaron en Cuba durante la regencia del Código de Defensa Social. En relación con esta temática, explica el profesor Pérez de AGREDA que "la tendencia mayoritaria actual, en la determinación legal de la pena, es hacia la ponderación de ésta con un amplio arbitrio judicial en busca, fundamentalmente, de la solución más beneficiosa al sancionado. (...) Es una concepción preventivo especial no sólo distinta, sino, en esencia, contraria a la que trajo el Positivismo en su tendencia de la "defensa social", donde se apreciaba la "peligrosidad criminal futura del individuo" para imponer una pena que, ajustada a esa predicción, procurara la supresión, la eliminación de esa peligrosidad y así la resocialización del transgresor. En esta nueva concepción preventivo-especial se aprecian las circunstancia personales del transgresor únicamente cuando aconsejan imponer una pena inferior a la que correspondería en proporción a la gravedad del hecho; ahora, cuando esas condiciones 
criminales y, en consecuencia, las ubican en la teoría de la sanción ${ }^{13}$. Sin embargo, últimamente se han alzado nuevas voces que, coherentes con las más avanzadas concepciones del sistema penal, han propuesto una solución intermedia o ecléctica.

\section{Fundamento dogmático}

Quienes defienden esta línea de pensamiento sostienen que la variación o modificación de la pena que conlleva la presencia de una circunstancia es consecuencia, a su vez, de que aquélla modifica accidentalmente el contenido de injusto o de culpabilidad, lo que supone la graduabilidad de estas magnitudes de la estructura del delito ${ }^{14}$.

Tanto la antijuricidad como la culpabilidad constituyen magnitudes graduables, cuyo contenido varía de acuerdo a la intensidad con que se manifiestan sus presupuestos fácticos en el caso particular ${ }^{15}$.

personales no sean positivas nunca serán tomadas en cuentas como criterios para agravar la pena en razón a la supuesta "peligrosidad criminal del sujeto" pues, al no ser objeto de valoración en el concepto del delito no puede determinar la medida de la pena. Si en el delito se aprecian antijuricidad y culpabilidad, la medida de la pena es, consecuentemente, proporcional a ellas". Vid. Rodríguez Pérez DE AgredA, Gabriel, "La adecuación judicial de la pena en el Código Penal cubano actual", Revista Cubana de Derecho No. 31, enero-junio 2008. UNJC, p. 69.

13 La primera posición es la dominante en la doctrina española, salvo algunos autores que, соmо Сово y Vives, González Cussac y Quintero Olivares, las estudian dentro de la teoría de la pena siguiendo el criterio sostenido por la dogmática alemana. Apud. Mir, Derecho Penal, cit. nota n. 7, p. 603.

14 Se adhieren a esta postura en la doctrina española Mercedes Alonso Álamo y Carmen Salinero Alonso. Sostiene esta última autora que "en definitiva, la variación de la pena abstracta prevista para un delito es consecuencia de la presencia de circunstancias que en unas ocasiones modifican-accidentalmente-el contenido del injusto o de la culpabilidad. Por tanto, las circunstancias aún teniendo efectos últimos o mediatos sobre la cantidad de pena, van a suponer un retoque al injusto, si es que afectan a la mayor o menor gravedad del hecho, o a la culpabilidad, si descansan en elementos de la imputación subjetiva". Vid. Salinero Alonso, Carmen, "Naturaleza jurídica, fundamento y comunicación de las Circunstancias Modificativas", en Libro homenaje al Doctor Marino BARBERO SANTOS, [s.ed.], [s.f.], p. 1310.

15 Сово, Derecho, cit. nota n. 1, p. 611. En la doctrina se han alzado voces reticentes a admitir la gradación de las categorías injusto y culpabilidad (o imputación personal, como prefiere denominarle hoy un sector de la dogmática), arguyendo que un hecho es lícito o no, y que un sujeto es culpable o no lo es. Al parecer, quienes sostienen esta posición desconocen los fundamentos que informan el moderno y más avanzado Derecho penal, que se rige sobre los principios de proporcionalidad y prohibición de exceso, lo que trae como consecuencia que de lege ferenda se admita la graduabilidad de tales elementos del delito en atención a que un hecho puede presentar mayor o menor desvalor -objetivo o subjetivo- de acción o resultado, o puede ser más o menos reprochable al autor. Obviamente no pueden ser valorados de la misma manera, desde el punto de vista de su gravedad, los delitos de lesión o daño y los delitos de peligro, lo cual viene determinado por el grado de ofensa al bien jurídico. Del mismo modo no puede reprochársele de igual forma el mismo comportamiento desarrollado por un sujeto que actúa bajo un error de prohibición vencible, que a uno que conoce plenamente la antijuricidad de su comportamiento. 
En efecto, el injusto es graduable por dos vías: por el desvalor de la acción, o porque el desvalor del resultado sea mayor o menor. El desvalor de la acción, fuera del tipo-circunstancias-, puede verse conformado por determinados móviles o intenciones que supongan su aumento o disminución, como ocurriría de estar presentes las circunstancias de "cometer el hecho por lucro o por otros móviles viles, o por motivos fútiles" (artículo 53-b del CP. ${ }^{16}$ ) o "haber obrado el agente obedeciendo a un móvil noble" (artículo 52-g del CP.), respectivamente.

En cuanto al desvalor del resultado, también puede ser modulado a través de determinadas circunstancias, que como "ocasionar con el mismo graves consecuencias" (artículo 53-c del CP.), determinan una agravación.

La culpabilidad es una estructura igualmente graduable a partir del análisis de los elementos que la conforman. Como ejemplo de la modulación del reproche culpabilístico en atención a la menor capacidad de culpabilidad -imputabilidadestán las circunstancias de "haber obrado la mujer bajo trastornos producidos por el embarazo, la menopausia, el período menstrual o el puerperio" (artículo 52-d del CP), o "haber obrado el agente en estado de grave alteración psíquica provocada por actos ilícitos del ofendido" (artículo 52-f del CP.), al igual que los supuestos de imputabilidad disminuida por la presencia de psicopatologías que no excluyen la capacidad de culpabilidad, según el apartado 2 del artículo 20 del Código Penal cubano.

Asimismo, la atenuante de la letra c) del artículo 52 "haber cometido el delito en la creencia, aunque errónea, de que se tenía derecho a realizar el hecho sancionable", incidirá sobre el elemento referido a la conciencia de la antijuricidad del acto; mientras que la prevista en el artículo 52-a) "obrar el agente bajo la influencia de una amenaza o coacción" desplegará sus efectos atenuatorios sobre el último eslabón a valorar en el momento de la formulación del juicio de reproche: la exigibilidad de un comportamiento distinto.

Reflexionando sobre la culpabilidad entendida como imputación personal, es decir, como la posibilidad de atribuir el injusto a su autor -juicio de reproche-, ha aclarado MiR Puig que "esta no puede crear un nuevo desvalor que no provenga ya del injusto penal, (...) no puede más que atribuir el injusto penal que concurra. Toda la fundamentación de la gravedad del hecho corresponde al injusto penal, la imputación personal sólo condiciona la atribución total o parcial de dicha gravedad"17.

En este mismo sentido, acota magistralmente el catedrático español que "la culpabilidad no añade al injusto ningún objeto específico de desvalor que contribuya a fundar la pena. (...) La pena no castiga la culpabilidad, sino la

${ }_{16}$ Código Penal de la República de Cuba, Ley No. 62, de 29 de diciembre de 1987. En lo adelante se le identificará como CP.

17 Cfr. MiR, Derecho Penal, cit. nota n. 7, p. 616. 
realización de un hecho no deseado, prohibido, antijurídico. La culpabilidad es sólo condición de atribución del injusto a su autor. Por eso no puede agravar, sino sólo en su caso, atenuar o excluir la pena"18.

En mérito a lo anterior habrá que concluir que la atenuación responde a una disminución del injusto o de la culpabilidad, y la agravación a un incremento de la antijuricidad.

\section{Fundamento político criminal}

La segunda dirección en torno al fundamento y ubicación sistemática de las circunstancias, es aquella que las sitúa fuera de la teoría del delito y en el seno de la teoría de la pena. González CuSSAC y otro grupo de autores ${ }^{19}$ rechazan el criterio de dividir las circunstancias, atendiendo a su incidencia en el injusto o en la culpabilidad, bajo el criterio de que todas las circunstancias responden a consideraciones político criminales, y más exactamente, a una mayor o menor necesidad de tutela $y$, en consecuencia, a una mayor o menor necesidad de pena ${ }^{20}$.

Esta ha sido la línea de pensamiento que ha llevado a sus últimas consecuencias el planteo de que las circunstancias, como elementos accidentales que son, no afectan la esencia ni existencia del delito y que sólo significan reglas de medición de la pena ${ }^{21}$.

Los defensores de esta postura sostienen que la existencia o inexistencia de circunstancias repercute en lo que es la consecuencia jurídica del delito, y por tanto a ella deben ser reconducidas, sobre la base de que la pena es un concepto sujeto a medición, prestándose mucho más a ello que el propio delito, sin desconocer la graduabilidad que pudiera concedérsele a sus elementos (culpabilidad y contenido de injusto) ${ }^{22}$.

\section{Posición intermedia}

Aun cuando la doctrina mayoritaria quiere ver la fundamentación de las circunstancias en una modulación de las categorías injusto o culpabilidad, los

${ }_{18}$ Cfr. Mir Puig, Santiago, Función de la Pena y Teoría del Delito en el Estado Social y Democrático de Derecho, 2ª Edición Revisada, Editorial BOSCH, Barcelona, 1982, p.103.

19 Vid. supra, nota al pie 13.

20 Alonso, Circunstancias, cit. nota n. 3.

${ }^{21}$ De esta opinión GonZález CusSAC, quien entiende que las circunstancias modificativas "deben verse como instrumentos de medición de la pena, y más específicamente, como aquellos elementos ofrecidos por el legislador que posibilitan la fijación del llamado marco legal concreto de la pena". Vid. GonzÁlEz, Presente, cit. nota n. 9.

22 Сово, Derecho, cit. nota n. 1, p. 611. 
defensores de esta posición no pueden desconocer que existen casos en que tal vinculación es difícil de establecerse, por no decir imposible.

Quienes, por el contrario, entienden que el campo de operaciones de las circunstancias es la pena, perciben igualmente que en determinados supuestos resulta complicado "aislar" a las circunstancias de valoraciones en torno a los juicios de antijuricidad o culpabilidad. Es decir, el reconocimiento de momentos político criminales o de caracterización dogmática en las circunstancias, con independencia de su mayor o menor peso, está poniendo de manifiesto que las "reglas generales" tienen excepciones ${ }^{23}$.

Representando esta postura ecléctica, ARIAS EIBE propone una diferenciación de las circunstancias modificativas de la responsabilidad penal en dos subcategorías: las circunstancias del delito y las circunstancias post-delictuales; de tal suerte que "mientras que las primeras poseen un fundamento esencialmente dogmático, por ir referidas a las categorías injusto o culpabilidad, las segundas poseen un fundamento estrictamente político-criminal"24.

Esta, que es, a nuestro juicio, la solución correcta, conlleva al entendimiento de que dentro de la teoría del delito, desde una óptica metodológicamente coherente, el lugar sistemático que debe ocupar el estudio de las circunstancias se corresponde con el momento en que tenga lugar la explicación de las categorías injusto y culpabilidad, las que dada su naturaleza graduable pueden verse aumentadas o disminuidas con independencia de que esta modificación despliegue su eficacia en el momento de la determinación del castigo; análisis que indiscutiblemente cobra efecto dentro del terreno de la teoría de la pena.

Las circunstancias, entonces, gradúan a la pena porque modulan en primer término al delito ${ }^{25}$, pero todo ello, sin preterir su función político criminal de tutela o de mayor o menor necesidad de pena, pues a la luz de las actuales concepciones del delito, injusto y culpabilidad no están ajenos a las exigencias político-criminales, debiendo admitirse que el catálogo de circunstancias que rodean al delito, en mayor o menor medida, están co-fundamentadas por determinadas razones preventivas ${ }^{26}$.

\footnotetext{
${ }^{23}$ Apud. Alonso, Circunstancias, cit. nota n. 3.

${ }^{24}$ ArIAS EIBE, Manuel J., "Graduación del desvalor y reproche en el marco de la estructura esencial y accidental del delito". En: http://www.unifr.ch//articulos/pdf/08mar07/arias_grad.pdf. [visitado el 29/11/08]

${ }^{25}$ Defiende esta posición, dentro del penalismo clásico, el maestro Luis JIMÉNEZ DE AsúA, quien sostuvo que "no parece propio tratarlas como datos para la medida de la pena (...) porque si agravan o atenúan la pena será por algo. Y ese algo es el grado de culpabilidad o peligrosidad". Vid. JIMÉNEZ DE AsúA, Luis, Principios de Derecho Penal, La Ley y el Delito, $3^{a}$ Edición, Editorial Abeledo-Perrot, Buenos Aires, 1958, p. 443.

${ }^{26}$ No puede negarse que la moderna construcción de la teoría del delito se erige sobre la base de principios político-criminales, atendiendo precisamente a que el Derecho penal hoy se concibe como
} 
Este criterio ha de entenderse como regla general, sin olvidar que pueden presentarse casos en que es imposible establecer la fundamentación de las circunstancias a partir de una modulación del injusto o de la culpabilidad.

Ciertamente, si atendemos a la circunstancia que el Código Penal cubano reconoce en la letra ch) del artículo 52 -"haber procedido el agente por impulso espontáneo a evitar, reparar o disminuir los efectos del delito, o a dar satisfacción a la víctima o a confesar a las autoridades su participación en el hecho, o a ayudar a su esclarecimiento"-, podrá entenderse lo planteado sobre ella por Salinero Alonso, en el sentido de que "siempre ha sido caballo de batalla para defender o criticar la vinculación de las circunstancias a la teoría del delito o fuera de ella"27.

Del análisis de esta circunstancia que la doctrina ha denominado arrepentimiento espontáneo, sin dudas podrá convenirse en que la misma ni afecta al tipo de injusto ni a la imputación personal, por cuanto se apoya en un fundamento fáctico posterior al hecho que ya ha alcanzado la consumación, o sea, luego de que se han perfeccionado las categorías de injusto y culpabilidad.

Evidentemente, el fundamento de esta atenuante no se halla en la gradación de las categorías que componen el contenido de la infracción punible, sino que descansa en razones político-criminales que, con un sentido utilitarista y pragmático, fomentan la reparación del daño y la persecución oficial, derivándose de esta actuación post delictum una menor necesidad de pena, tanto desde un punto de vista preventivo especial -menor peligrosidad apreciable en quien reconoce su actuación delictiva e interioriza la significación del bien jurídico a través de la reparación del daño-, como preventivo general positivo -la actitud del delincuente conduce a la afirmación de la conciencia social sobre la norma y de su vigencia de cara a la comunidad.

un Derecho penal orientado a las consecuencias, convirtiendo la comprobación empírica de las consecuencias que este persigue en un elemento fundamental para la interpretación del conjunto normativo que interesa al jurista. Un Derecho penal concebido de tal modo necesita verificar la justeza de las decisiones de las distintas instancias jurídico-penales, aunque se nos presenten como correctas desde el punto de vista normativo. Así, deberá cuestionarse el legislador penal si es necesario recurrir a esta rama del Derecho cuando sean suficientes otros medios de solución jurídica menos radicales (Derecho Laboral, Derecho de Familia etc.); si las prohibiciones penales se refieren a conductas que "realmente" producen un daño y, por tanto, lesionan un bien jurídico; si el aumento de la gravedad de la pena produce el esperado efecto intimidatorio. También el juez penal tendrá que reflexionar, especialmente en el momento de determinación de la pena, sobre cuestiones trascendentales que el legislador deja en manos de su discrecionalidad. Cfr. HASSEMER, Winfried; MuÑoz Conde, Francisco, Introducción a la Criminología y al Derecho Penal, Editorial Tirant lo Blanch, Valencia, 1989, pp. 15 y ss. En el caso específico de Cuba, por ejemplo, el Tribunal deberá razonar sobre la viabilidad de sustituir la pena privativa de libertad por alguna de las subsidiarias que reconoce la ley (Trabajo Correccional con o sin Internamiento, Limitación de Libertad) o de remitirla condicionalmente, o apreciar la disminuyente por razón de la edad, etc.

27 Salinero, Naturaleza, cit. nota n. 14, p. 1312. 
De lo dicho hasta aquí puede concluirse que las circunstancias modificativas tienen un doble fundamento: dogmático y político criminal. En dependencia del caso prevalecerán las razones político-criminales sobre las dogmáticas, o viceversa; mientras que en otras oportunidades, sólo las primeras cobrarán relevancia. Pero en todas las situaciones, sólo las particularidades del caso concreto podrán determinar la preponderancia de uno u otro aspecto en la valoración del fundamento de la circunstancia.

\section{Lo CIRCUNSTANCIAL EN LO IMPRUDENTE. Un REEXAMEN DEL ASUNTO}

Afirmada la incompatibilidad de circunstancias modificativas con el ilícito imprudente -que en nuestro país ha constituido tradicionalmente un sólido criterio de la Sala de lo Penal de TSP, asimilado a lo que en otras latitudes se identifica con la cómoda posición de «línea jurisprudencial dominante»-, corresponde ahora desarrollar un análisis crítico en torno a dicha cuestión.

El fundamento de esta inveterada postura académica parte de que, para la apreciación de tales elementos accidentales, se precisa que el agente conozca la base fáctica de la circunstancia en cuestión y al menos, se aproveche de ella; lo que de ordinario ocurre en los delitos dolosos, ya que en ellos el sujeto conoce todos y cada uno de los presupuestos típicos, así como las circunstancias vinculadas a aquéllos, y quiere la realización del hecho delictuoso. Pero es obvio que esto no acontece en la conducta imprudente, en la que resulta irrelevante la finalidad que anima la actuación del sujeto, toda vez que la desaprobación recae sobre la forma descuidada en que aquel ejecuta el comportamiento que ocasiona un resultado lesivo no querido, pero sí previsible y evitable de haberse observado el deber de cuidado objetiva y subjetivamente exigible ${ }^{28}$.

En este sentido, señalaba el profesor Aldo Prieto Morales que en los delitos imprudentes "rige el principio de la previsibilidad, pero no el de la voluntariedad, característica del dolo, por lo que no resulta justo ni correcto apreciarlas" ${ }^{\prime 29}$.

Desde nuestro punto de vista, este criterio es absolutamente válido en relación con aquellas circunstancias que poseen un típico fundamento dogmático, cuya apreciación está sujeta a que sean buscadas, o al menos aprovechadas, por el comisor.

Sin embargo, esas razones pierden toda eficacia de cara a aquellas circunstancias que gozan de un exclusivo fundamento político-criminal, con nula influencia sobre el injusto o la culpabilidad, por estar vinculadas a los fines de la sanción, como acontece en aquellas circunstancias de naturaleza pre-delictual

${ }^{28}$ Con mayor amplitud, Vid. Muñoz, Derecho Penal, cit. nota n. 6, p. 284.

29 Prieto Morales, Aldo, Lo Circunstancial en la Responsabilidad Penal, Editorial de Ciencias Sociales, La Habana, 1983, p. 241. 
-como la prevista en el artículo 52-e- o post-delictual -como es el caso del artículo 52-ch-, que no modifican la gravedad de la infracción penal en razón de un menor injusto o una menor culpabilidad, porque no es posible analizar el contenido de estas categorías cuando todavía no se ha iniciado la dinámica delictiva-ejecución o, excepcionalmente, la preparación-, ni con posterioridad a la consumación, cuando ya han quedado completamente perfeccionadas.

En estos casos no se trata de determinar si el hecho es menos negativo, sino que las valoraciones deben estar enfocadas en la personalidad del sujeto y en las posibilidades de alcanzar el cumplimiento de los fines programáticos de la sanción, reconocidos en el artículo 27 del texto punitivo en vigor. La carga de prevención especial que ha de contener la pena resulta disminuida cuando deba recaer en un sujeto sobre quien puede fundarse la prognosis fiable de que las finalidades de la punición serán alcanzadas con una respuesta penal menos intensa, en aras de una menor necesidad de pena ${ }^{30}$.

Obviamente, el criterio de apreciar estos elementos accidentales en los delitos imprudentes se limita, exclusivamente, a circunstancias atenuantes, las que deben ser acogidas sin reservas en coherencia con los principios garantistas del Derecho Penal, ya que ellas implican limitar la intervención punitiva del Estado $^{31}$.

Siendo así, hay que admitir la posibilidad de apreciar en delitos culposos las circunstancias contenidas en los incisos ch) y e) del cuadro de atenuantes previsto en el artículo 52 (arrepentimiento espontáneo y conducta destacada), que por su fundamento político-criminal -razones utilitaristas y preventivoespeciales- resultan plenamente congruentes con dicha forma de imputación subjetiva.

Un reciente pronunciamiento de nuestro máximo órgano de justicia augura, al parecer, el inicio de un cambio de postura en este sentido, y aunque aún trata el asunto con cierta timidez, merece destacarse como colofón de la posición aquí asumida. Se trata de la Sentencia № 853, de 24 de marzo de 2010, dictada por la Sala de Casación ${ }^{32}$, que en un delito complejo y culposo de homicidio y daños

\footnotetext{
30 Opina StRAtenWERTH que "a la culpabilidad ha de añadirse siempre la necesidad práctica de una pena", y aclara Roxın que "una conducta merecedora de pena sólo estará necesitada de pena si se añade una necesidad preventiva de punición". Cfr. Roxın, Claus, Derecho Penal, Parte General, Tomo I -Fundamentos. La Estructura de la Teoría del Delito-, Traducción y notas de Luzón Peña, DiegoManuel; Díaz y García Conlledo, Miguel; de Vicente Remesal, Javier, $2^{a}$ Edición, Editorial Civitas, Madrid, 1997, p. 983.

31 Apud. Bustos Ramírez, Juan, El Delito Culposo, Editorial Jurídica de Chile, Santiago-Chile, 2002, p. 113.

32 La Sala estuvo integrada por los compañeros Tomás Betancourt PeÑa (Presidente), Eulogio Roque Días, María Caridad Bertot Yero (ponente), Luis Olayo Hernández Márquez y Luis Reynaldo Molina HERNÁNDEZ.
} 
cometidos en ocasión de conducir vehículos en las vías públicas, resolvió en lo atinente: "Que la cuestión de la apreciación de las circunstancias de atenuación y agravación de la responsabilidad penal en los delitos cometidos por imprudencia es un tema tratado en el campo de la doctrina científica en el sentido de que son de apreciación unas y otras siempre que sean compatibles con la índole del delito por imprudencia, rechazándose tan solo las que se vinculen de modo especial al delito intencional; de manera que no es válida la posición sostenida en la sentencia por la Sala actuante, al afirmar que ante la comisión de este tipo de hechos se excluye todo lo referido a las modalidades circunstanciales del ilícito, lo que determinó que no se motivara, de manera particular, la antes mencionada circunstancia mitigatoria de la responsabilidad penal alegada por el recurrente".

\section{IDEAS CONCLUSIVAS}

Las circunstancias modificativas de la responsabilidad penal son elementos accidentales del delito (accidentalia delicti), por cuanto no determinan su existencia, sino que importan sólo a los efectos de la gravedad de la infracción.

El estudio y la ubicación sistemática de las circunstancias deben reconducirse a la teoría del delito, en unos casos; y a la teoría de la pena, en otros. Por ello el fundamento de las circunstancias debe enmarcarse dentro de una posición mixta, que reconozca tanto razones dogmáticas como político-criminales, lo cual habrá de determinarse de acuerdo a la circunstancia en particular.

En los delitos imprudentes, no es posible apreciar circunstancias agravantes. Las atenuantes pueden valorarse siempre que se fundamenten en razones político-criminales. Así, podrán apreciarse en los delitos imprudentes las causas de mitigación de la pena previstas en los apartados ch) y e) del artículo 52 del vigente Código Penal cubano.

\section{BibLiOGRAFíA}

Alonso Álamo, Mercedes, "Circunstancias del delito e inseguridad jurídica", Cuadernos y Estudios de Derecho Judicial, Consejo General del Poder Judicial, Edición Especial para IBERIUS, 2004.

ARIAS EIBE, Manuel J., "Graduación del desvalor y reproche en el marco de la estructura esencial y accidental del delito". En: http://www.unifr.ch//articulos/ pdf/08mar07/arias_grad.pdf. [visitado el 29/11/08].

Bustos Ramírez, Juan, El Delito Culposo, Editorial Jurídica de Chile, SantiagoChile, 2002.

Cobo del Rosal, Manuel; Vives Antón, Tomás S., Derecho Penal, Parte General, $2^{a}$ Edición, Editorial Tirant Lo Blanch, Valencia, 1988.

Garrido Montt, Mario, Derecho Penal, Parte General, Tomo I, $1^{\text {a }}$ Edición, Editorial Jurídica de Chile, Santiago-Chile, 2001. 
GonzÁlez Cussac, José L., Teoría General de las circunstancias modificativas de la responsabilidad criminal, Editorial del servicio de Publicaciones de la Universidad de Valencia, 1983.

, "Presente y Futuro de las Circunstancias Modificativas". En: Cuadernos y Estudios de Derecho Judicial, Consejo General del Poder Judicial, Edición Especial para IBERIUS, 2004.

Hassemer, Winfried; Muñoz Conde, Francisco, Introducción a la Criminología y al Derecho Penal, Editorial Tirant lo Blanch, Valencia, 1989.

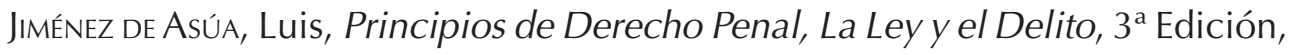
Editorial Abeledo-Perrot, Buenos Aires, 1958.

Larenz, K., Metodología de la Ciencia del Derecho, 2ª Edición, Traducida por M. Rodríguez Molinero, Barcelona, 1980.

Mir PUIG, Santiago, Función de la Pena y Teoría del Delito en el Estado Social y Democrático de Derecho, $2^{a}$ Edición Revisada, Editorial BOSCH, Barcelona, 1982.

Derecho Penal, Parte General, $7^{a}$ Edición, Editorial Reppertor, Barcelona, 2005.

Muñoz Conde, Francisco; García Arán, Mercedes, Derecho Penal, Parte General,

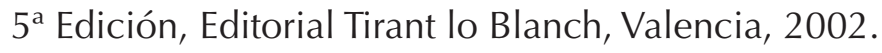

Prieto Morales, Aldo, Lo Circunstancial en la Responsabilidad Penal, Editorial de Ciencias Sociales, La Habana, 1983.

Rivero García, Danilo; “¿Espontánea confesión o ayuda al esclarecimiento? Polémica entre el discurso legal y la práctica", en Rivero García, Danilo; Temas permanentes del Derecho Procesal y del Derecho Penal, Ediciones ONBC, La Habana, 2010.

, “¿Vida ejemplar o conducta destacada?", en Rivero García, Danilo; Temas permanentes del Derecho Procesal y del Derecho Penal, Ediciones ONBC, La Habana, 2010.

Rodríguez Pérez de Agreda, Gabriel, "La adecuación judicial de la pena en el Código Penal cubano actual", Revista Cubana de Derecho № 31, enerojunio 2008. UNJC.

Roxın, Claus, Derecho Penal, Parte General, Tomo I -Fundamentos. La Estructura de la Teoría del Delito-, Traducción y notas de LuZón PeÑa, Diego-Manuel; Díaz y García Conlledo, Miguel; De Vicente Remesal, Javier, 2ª Edición, Editorial Civitas, Madrid, 1997.

Salinero Alonso, Carmen, "Naturaleza jurídica, fundamento y comunicación de las Circunstancias Modificativas", en Libro homenaje al Doctor Marino BARBERO SANTOS. 